\title{
Seasonal variation and sources of low molecular weight organic acids in precipitation in the rural area of Anshun
}

\author{
ZHANG YanLin ${ }^{1,2 *}$, LEE XinQing ${ }^{2 *}$, CAO Fang $^{1} \&$ HUANG DaiKuan ${ }^{2}$ \\ ${ }^{1}$ State Key Laboratory of Organic Geochemistry, Guangzhou Institute of Geochemistry, Chinese Academy of Sciences, Guangzhou 510640, China, \\ ${ }^{2}$ State Key Laboratory of Environmental Geochemistry, Institute of Geochemistry, Chinese Academy of Sciences, Guiyang 550002, China
}

Received July 8, 2010; accepted November 16, 2010

\begin{abstract}
Low molecular weight (LMW) organic acids are important and ubiquitous chemical constituents in the atmosphere. A comprehensive study of the chemical composition of precipitation was carried out from June 2007 to June 2008 at a rural site in Anshun, in the west of Guizhou Province, China. During this period, 118 rainwater samples were collected and the main LMW carboxylic acids were determined using ion chromatography. The average $\mathrm{pH}$ of rainwater was 4.89 which is a typical acidic value. The most abundant carboxylic acids were formic acid (volume weight mean concentration: $\left.8.77 \mu \mathrm{mol} \mathrm{L}^{-1}\right)$ and acetic acid $\left(6.90 \mu \mathrm{mol} \mathrm{L} \mathrm{L}^{-1}\right)$, followed by oxalic acid $\left(2.05 \mu \mathrm{mol} \mathrm{L}^{-1}\right)$. The seasonal variation of concentrations and wet deposition fluxes of organic acids indicated that direct vegetation emissions were the main sources of the organic acids. Highest concentrations were observed in winter and were ascribed to the low winter rainfall and the contribution of other air pollution sources northeast of the study area. The ratio of formic and acetic acids in the precipitation $\left([F / A]_{T}\right)$ was proposed as an indicator of pollution source. This suggested that the pollution resulted from direct emissions from natural or anthropogenic sources. Comparison with acid precipitation in other urban and rural areas in Guizhou showed that there was a decreasing contribution of LMW organic acids to free acidity and all anions in rainwater from urban to remote rural areas. Consequently, it is necessary to control emissions of organic acids to reduce the frequency of acid rain, especially in rural and remote areas.
\end{abstract}

precipitation, acid rain, organic acids, sources, Guizhou

Citation: Zhang Y L, Lee X Q, Cao F, et al. Seasonal variation and sources of low molecular weight organic acids in precipitation in the rural area of Anshun. Chinese Sci Bull, 2011, 56: 1005-1010, doi: 10.1007/s11434-011-4411-5

Acid rain is an important global environmental issue. Although rainwater acidity is historically linked to inorganic acids such as $\mathrm{H}_{2} \mathrm{SO}_{4}$ and $\mathrm{HNO}_{3}$, a number of studies have shown the important contribution of organic acids, mainly formic, acetic and oxalic acids [1-7]. These organic acids account for as much as $80 \%-90 \%$ of the acidity in remote areas of the world [8] and contribute $25 \%-65 \%$ of the rainwater acidity in industrial and urban areas $[6,9,10]$. The presence of formic and acetic acids in the atmosphere can influence $\mathrm{pH}$-dependent chemical reactions in clouds and also have a negative effect on aquatic and terrestrial ecosystems [11]. Also, these acids have been shown to be sig-

*Corresponding authors (email: dryanlinzhang@gmail.com; xinqinglee@hotmail.com) nificant constituents of water soluble organic compounds in cloud condensation nuclei(CCN) and thus may alter the chemical and physical properties of these aerosols and enhance their capability as CCN [2,10,12-14].

The distribution and sources of organic acids in precipitation have not yet been properly identified in China. Studies have been carried out in a few large or industrial cities, including Beijing, Shenzhen, and Guiyang, by Peking University [6,15], the Chinese Academy of Sciences [5,7,10,16] and the Chinese Academy of Meteorological Sciences [17] since the 1980s. In comparison, studies on organic acids in remote and/or rural sites have been scant. Guizhou Province is one of the most serious areas of acid rain incidence in southwest China, and has already been adversely affected 
by substantial environmental degradation arising from air pollution. This paper describes the chemical characteristics and sources of organic acids in precipitation at a semi-urban site in Guizhou during June 2007 to June 2008. The major objectives of this paper are (1) to gain an initial understanding of the distribution and seasonal variations of organic acids in the precipitation; (2) to evaluate the possible sources of these species by comparison with other results in the world; and (3) to provide a database for research on climate change and atmospheric chemistry related to organic acids.

\section{Experimental}

\subsection{Sample location}

The sampling site is located in the west of Guizhou Province in China (Figure 1). Rainwater samples were collected from June 2007 to June 2008 on the roof of a building, $15 \mathrm{~m}$ above the ground, in the Maomaodong Ecological Preserve $\left(26.4^{\circ} \mathrm{N}, 106.2^{\circ} \mathrm{E}, 1046 \mathrm{~m}\right)$, which is $15 \mathrm{~km}$ away from the center of the city of Anshun. The closest major road passes this site at a distance of about $3 \mathrm{~km}$. There are no obvious pollution sources nearby.

\subsection{Sample collection and analysis}

Rainwater samples were collected using an automatic precipitation sampler (APS-2B, Changsha Xianglan Scientific Instruments Co., China), which automatically collects a sample from every rain event. Samples were stored at $-18^{\circ} \mathrm{C}[18]$ before chemical analysis within two weeks. The procedures for analytical measurements have been described previously [10]. Quality assurance procedures included the routine running of blanks and control samples as well as replicate samples. Blank and stability tests showed no detectable peaks. Carboxylic acids and major anions including $\mathrm{F}^{-}, \mathrm{CH}_{3} \mathrm{COO}^{-}, \mathrm{CH}_{3} \mathrm{CH}_{2} \mathrm{COO}^{-}, \mathrm{HCOO}^{-}, \mathrm{CH}_{3} \mathrm{SO}_{3}^{-}$, $\mathrm{CH}_{3} \mathrm{COCOO}^{-}, \mathrm{NO}_{2}{ }^{-}, \mathrm{Cl}^{-}, \mathrm{NO}_{3}{ }^{-}, \mathrm{SO}_{4}{ }^{2-},(\mathrm{COO})_{2}{ }^{2-}$ and $\mathrm{PO}_{4}{ }^{3-}$, were simultaneously determined by Dionex ICS-90 ion chromatography equipped with an AS11-HC separation column within $30 \mathrm{~min}$. The gradient eluent of $\mathrm{KOH}$ was generated from reagent free controller (RFC-30). The relative standard deviations (RSD\%) were below 5\%. Quantitative recoveries of spiked samples ranged from $80 \%$ to $120 \%$.

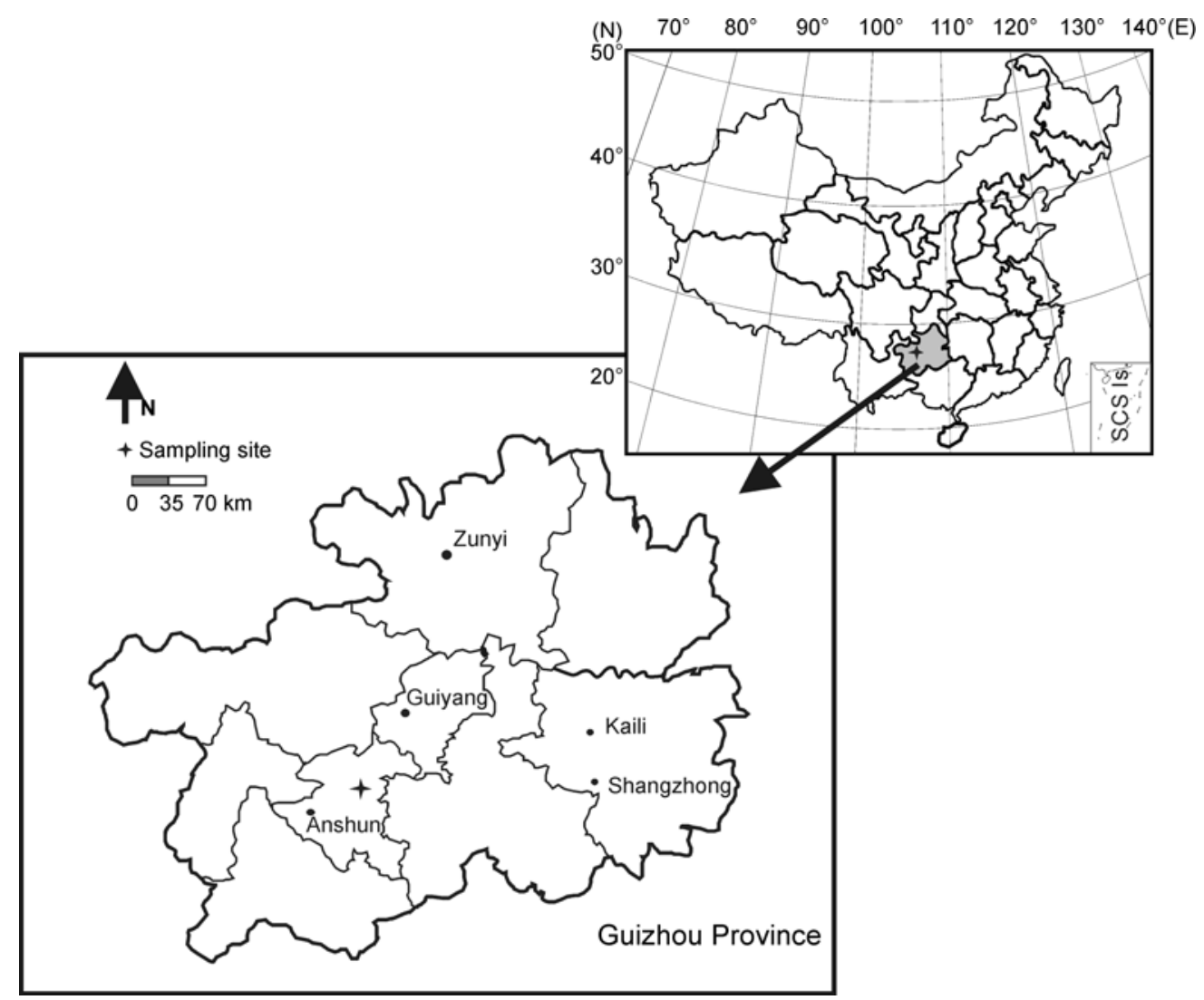

Figure 1 The location of the sampling site in Guizhou Province, China. 


\section{Results and discussion}

\subsection{Concentrations of organic acids in rainwater}

The $\mathrm{pH}$ of rainwater in Anshun varied from 3.57 to 7.09 with an annual volume-weighted average (VWA) of 4.89 which is a typical acidic value. About $56.0 \%$ of the rainwater samples had a $\mathrm{pH}$ less than 5.6, which is the $\mathrm{pH}$ of water at equilibrium with atmospheric $\mathrm{CO}_{2}$ and is usually used as a criterion for acid rain. As illustrated in Table 1, the six carboxylic acids present in the rainwater were all monocarboxylic except for oxalic acid (a dicarboxylic acid) and pyruvic acid (an oxy-carboxylic acid). The most abundant carboxylic acids were formic acid (volume weight

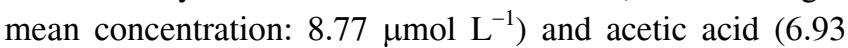
$\left.\mu \mathrm{mol} \mathrm{L} \mathrm{L}^{-1}\right)$, followed by oxalic acid $\left(2.84 \mu \mathrm{mol} \mathrm{L} \mathrm{L}^{-1}\right)$; these contributed $46.2 \%, 36.5 \%$ and $14.9 \%$ of the total carboxylic acids.

Organic acids accounted for $12.6 \%$ of the total anion concentration. Assuming that all the measured carboxylic anions are contributed by their respective acid forms, the maximum contribution of these measured carboxylic ions to the free acidity of the rainwater can be calculated [13] using an already widely applied method [2,21,25,26]. This showed that formic, acetic and oxalic acids accounted for $19.2 \%$ (range $0.2 \%-48.8 \%$ ), $5.9 \%$ (range $0.1 \%-37.7 \%$ ) and $7.8 \%$ (range $0.5 \%-33.9 \%$ ) of the free acidity. Overall, the three major carboxylic acids contributed $32.9 \%$ to the free acidity (range $0.9 \%-98.9 \%$ ). The carboxylic acids therefore had an important effect on the chemical constituents and acidity of the rainwater.

\subsection{Seasonal variation of organic acids in precipitation}

The seasonal variations of organic acids in the precipitation are shown in Figure 2. In general, the concentrations of formic and acetic acids displayed the seasonal variation pattern: winter $>$ spring $>$ summer $>$ autumn. Both biogenic emissions and meteorological conditions have been regarded as important factors influencing the seasonal variations of carboxylic acids in rainwater [19]. The carboxylic acids decreased with increased rainfall during the rainy

Table 1 Concentrations ( $\mu \mathrm{mol} / \mathrm{L})$ and detection ratios of organic acids in precipitation collected at the sampling site

\begin{tabular}{cllrc}
\hline & Mean & Min & Max & $\begin{array}{c}\text { Detection } \\
\text { ratio (\%) }\end{array}$ \\
\hline Acetic acid & 6.93 & 0.53 & 69.69 & 82 \\
Propanoic acid & 0.19 & 0.030 & 79.65 & 13 \\
Formic acid & 8.77 & 0.018 & 115.96 & 91 \\
Methane sulfuric acid (MSA) & 0.038 & 0.0030 & 0.49 & 69 \\
Pyruvic acid & 0.23 & 0.0060 & 4.19 & 57 \\
Oxalic acid & 2.84 & 0.14 & 10.14 & 96 \\
\hline
\end{tabular}

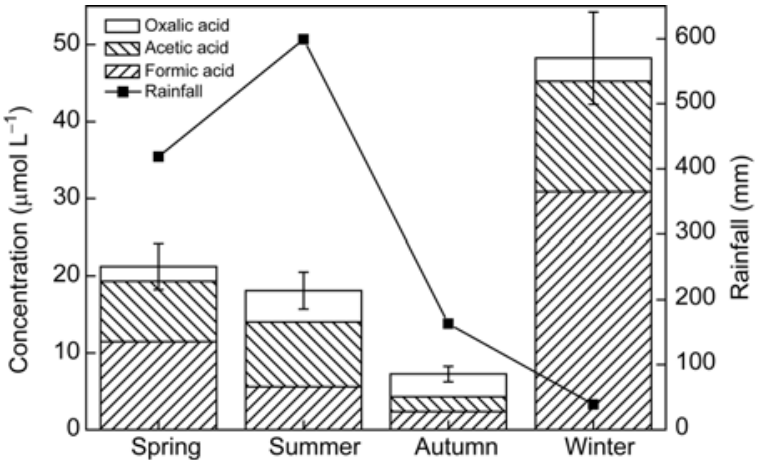

Figure 2 Seasonal variations of rainfall $(\mathrm{mm})$ and volume-weighted average (VWA) concentrations $(\mu \mathrm{mol} / \mathrm{L})$ of organic acids in precipitation collected at the sampling site.

seasons of spring and summer, because of the dilution effect. This was confirmed by the negative relationship $(P=0.05)$ between organic acid concentrations and rainfall. During the autumn in Anshun, the intensity of plant growth slowed down, and thus the concentration of organic acids decreased significantly because of reduced vegetation emissions. Surprisingly, the highest concentrations of organic acids were found in winter. This is attributed to both the frequency of rain events and the amounts of rainfall being limited in winter resulting in less potential for effective removal of organic pollutants in the atmosphere by wet deposition and a consequent increase in the concentrations of the carboxylic acids. Also, concentrations of particulate matter in the atmosphere in winter have been shown to be higher than in the summertime because of small rain amounts (less than 1 $\mathrm{mm}$ ) and longer duration between rain events [20]. This particulate matter was deposited into the collected samples during the dry season. Finally, the study site was influenced by the northeast monsoon with a prevailing polluted continental air mass from the northeast during winter (HYSPLIT 4.8). As a result, the higher concentrations in winter might be attributable to the industrial plume from the upwind urban areas of Zunyi and Chongqing. The lower concentrations of organic acids found in summer are during the Southern Asian Monsoon period with high rainfall amounts when air masses originate from marine storms in the Indian Ocean or the South China Sea. Highest concentrations of organic acids in winter were also reported in Hong Kong by Tanner [3].

Seasonal variations in the wet deposition flux of organic acids in precipitation were in the order: summer $>$ spring $>$ winter $>$ autumn (Figure 3 ). This was influenced by both the concentration of organic acids in precipitation and amounts of rainfall and reflected the real emissions of organic acids at the study site. Seasonal variation in the extent of vegetation emissions might be the main reason for the seasonal variation of wet deposition fluxes of organic acids because vegetation and plant cover of the study site was about $40.5 \%$. The rainwater samples were classified into two 


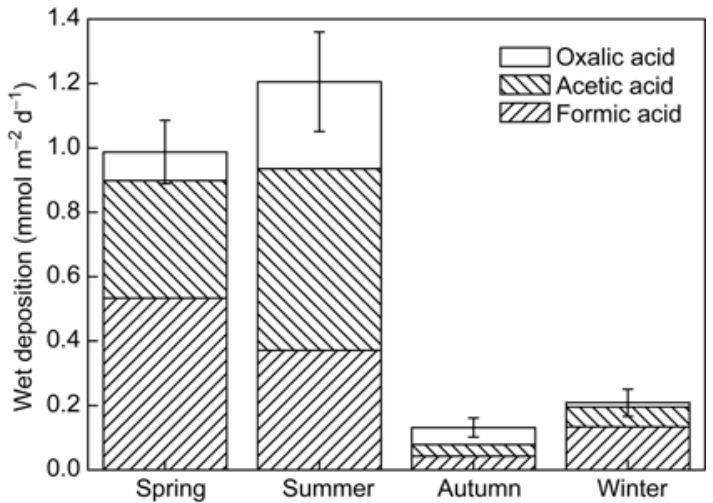

Figure 3 Seasonal variations of wet deposition fluxes of organic acids in precipitation collected at the sampling site.

groups based on the growing season (spring and summer) and non-growing season (autumn and winter). The fluxes of formic and acetic acids were much higher during the growing season than during the non-growing season which might be attributable to the low winter and autumn rainfall. The observed relationship with the growing season is consistent with results from northern California in the USA [21] and the Northwest Region of Spain [2] suggesting biogenic emissions might be the main sources of the organic acids. However, it was difficult to explain the fact that the flux in autumn was greater than that in winter because the activities of biomass burning and plant growth in autumn were more significant than in winter. Both wet and dry deposition fluxes need to be considered and investigated in further studies.

\subsection{Correlation analysis among organic acids}

Formic, acetic and oxalic acid concentrations were subjected to correlation analysis by SPSS 11.0 to understand their possible sources. The results are shown in Table 2. A significant positive correlation was found between formic and acetic acids suggesting that these two species were emitted from common sources, and/or they were controlled by a common reaction. Significant correlations between them have also been found in many other studies [6,13,19-21]. Formic acid was also found to be correlated with oxalic acid, which was also found in rainwater in Shenzhen [6] and Guiyang [19], indicating they had similar direct sources and/or secondary formations of previous gases to those in this study. However, the correlation coefficient was much less than that between formic and acetic acids, which was attributed to more complex sources of oxalic acid, such as secondary photochemical oxidation of VOCs from traffic emissions.

\subsection{Formic and acetic acid $[F / A]$ ratios}

Various studies have examined the use of the $F / A$ ratio in the gas phase or in rainwater as an indicator of the relative contribution of direct emissions and secondary formation in the gaseous phase. The resulting ratio may be taken as an indicator of direct emission (low ratio, $F / A<1$ ) and in situ formation by photochemical processes in the gaseous phase (high ratio, $F / A>1$ ) $[3,12,22-24]$. However, the $F / A$ ratio in the liquid phase (e.g. rainwater) is more complicated than that in the gas phase. By assuming that all of the measured formate and acetate ion concentrations were contributed from the corresponding acid forms, the $F / A$ ratio above (in the gaseous phase) can be changed to be in the liquid phase according to Henry's Law and the Ideal Gas Equation as follows:

$$
[F / A]_{T}=\frac{K_{H 1}\left(\left[\mathrm{H}^{+}\right]+K_{\mathrm{a}}\right)}{K_{H 2}\left(\left[\mathrm{H}^{+}\right]+K_{\mathrm{b}}\right)} \times[F / A],
$$

where $[F / A]_{T}$ is the ratio of the concentration of formic or acetic acid determined by $\mathrm{IC},\left[\mathrm{H}^{+}\right]$is calculated from the $\mathrm{pH}$ value, $K_{H 1}=5.6 \times 10^{3} \mathrm{~mol} \mathrm{~L}^{-1} \mathrm{~atm}^{-1}, K_{H 2}=8.8 \times 10^{3} \mathrm{~mol} \mathrm{~L}^{-1} \mathrm{~atm}^{-1}, K_{\mathrm{a}}=$ $1.77 \times 10^{-4}(T=298.15 \mathrm{~K},[25]),[F / A]=1$.

The curve of the equation and the monthly mean $[F / A]_{T}$ ratios for the 12 months of the sampling period are plotted in Figure 4. If the origin is mainly direct emissions, the $[F / A]_{T}$ values should be below the curve $(F / A<1)$, while if a secondary source dominates the origin, the $[F / A]_{T}$ values should be above the curve. As shown in Figure 4, all of the plots of $[F / A]_{T}$ values were below the curve, indicating that primary sources including vehicular emissions, biomass burning, and soil and vegetation emissions were the dominant sources of formic and acetic acids and that secondary

Table 2 Correlation analysis among organic acids ${ }^{\text {a) }}$

\begin{tabular}{cccc}
\hline & Acetic acid & Formic acid & Oxalic acid \\
\hline Acetic acid & 1 & - & - \\
Formic acid & $0.80(* *)$ & 1 & - \\
Oxalic acid & $0.21(*)$ & $0.44(* *)$ & 1 \\
\hline
\end{tabular}

a) $* P<0.05 ; * * P<0.01$.

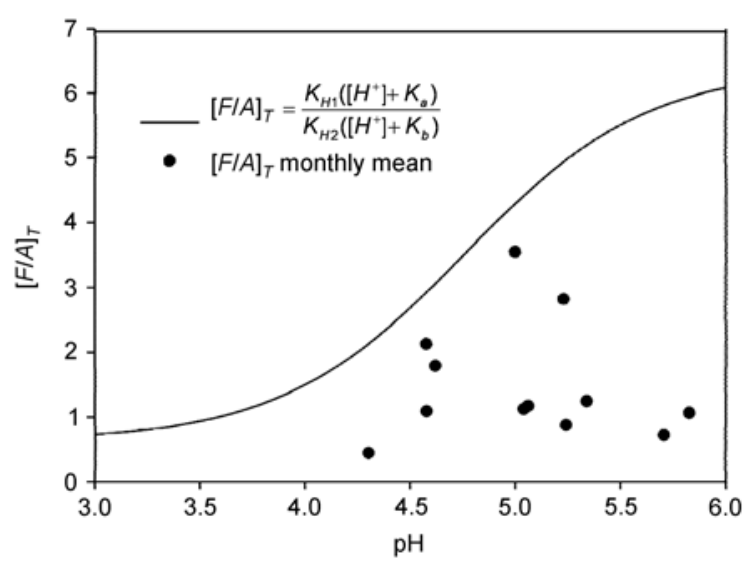

Figure 4 The curve of the equation of $[F / A]_{T}$ and the monthly mean of $[F / A]_{T}$ in precipitation during the twelve month sampling period. 
formation by photochemical processes in the gaseous phase was not the main source of these two species.

\subsection{Comparison with other sites in Guizhou}

To investigate the spatial distribution of organic acids in precipitation within Guizhou Province, data from another three sites from previous studies were used. These sites were Guiyang [7], Zunyi [5] and Shangzhong [7] together with Anshun, representing moderately polluted, severely polluted, remote/background and rural/clean sites, respectively. The spatial distributions within these sites of $\mathrm{pH}$ values, concentrations of organic acids, the contributions to the total free acidity, and anions from organic acids in precipitation are presented in Figure 5. The degree of rainwater acidification decreased from Zunyi to Guiyang to Anshun and Shangzhong, in accordance with the pollution characteristic of these sites. The $\mathrm{pH}$ values of rainwater in urban sites were much lower than for the more remote sites, indicating that anthropogenic pollution was the main source of rainwater acidification in Guizhou. When air pollution is produced in the typical mountain region cities, it diffuses and is removed with difficulty, which causes serious adverse effects on corresponding ecosystems as well as on human health. The highest concentration of organic acids was found in Guiyang, while lowest levels were found in Shangzhong. Compared to the other three sites, Shangzhong is less influenced by anthropogenic effects and vegetation emissions were the main sources of organic acids [19], implying that anthropogenic sources of organic acids should be of great importance in urban and industrially-influenced sites. The contributions to acidity and the total anions from organic acids in rainwater in Shangzhong were $32.9 \%$ and
$58 \%$, respectively (Figure 5), which were much higher than those in other sites. These figures clearly demonstrate that rainwater acidification is mainly caused by inorganic pollutions such as $\mathrm{SO}_{2}$ and $\mathrm{NO}_{x}$ in urban and semi-urban sites in Guizhou Province. However, carboxylic acids significantly affect the acidification and chemical constituents of the rainwater in remote and rural sites.

\section{Conclusions}

(1) The most abundant carboxylic acids were formic acid

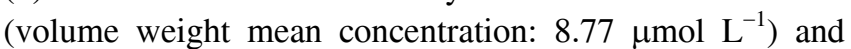
acetic acid $\left(6.90 \mu \mathrm{mol} \mathrm{L} \mathrm{L}^{-1}\right)$, followed by oxalic acid $(2.05$ $\left.\mu \mathrm{mol} \mathrm{L} \mathrm{L}^{-1}\right)$. The seasonal variation of concentrations and the wet deposition flux of organic acids changed in order as follows: winter $>$ spring $>$ summer $>$ autumn, and summer $>$ spring $>$ winter $>$ autumn.

(2) A significant positive correlation was found between formic and acetic acids consistent with previously published results. These two most abundant organic acids in rainwater might be emitted from common sources, and/or controlled by a common reaction. Use of the ratio of formic and acetic acids in the precipitation $\left([F / A]_{T}\right)$ as an indicator of pollution source, showed that it resulted from direct emissions from natural or anthropogenic sources such as vegetation, biomass burning and traffic.

(3) Acidification in rainwater is mainly caused by inorganic pollution in urban and semi-urban sites in Guizhou Province. However, carboxylic acids significantly affect acidification and the chemical constituents of rainwater in remote and rural sites. Consequently, it is necessary to control emissions of organic acids to reduce the frequency of acid rain, especially in these areas.

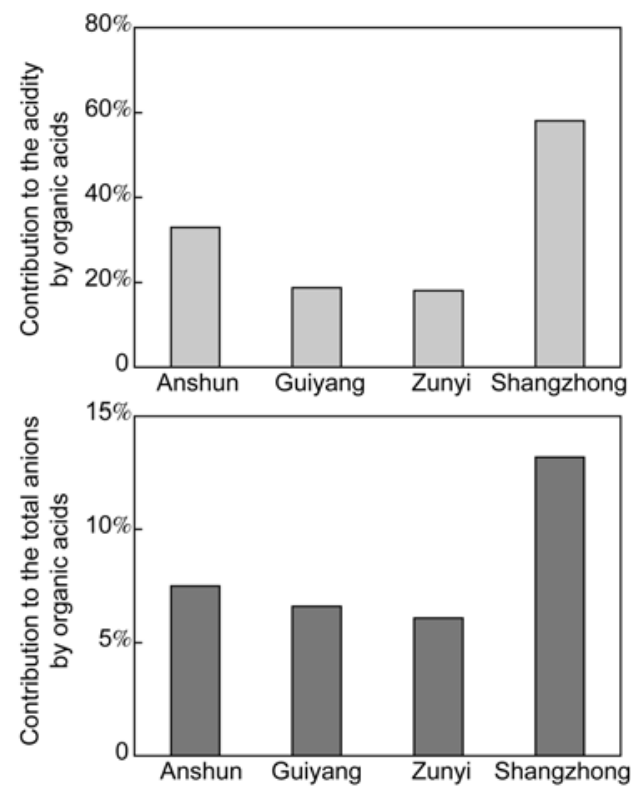

Figure 5 The spatial distributions of $\mathrm{pH}$ values, concentrations of organic acids, the contributions to the total free acidity, and the total anions from organic acids in precipitation in selected sites in Guizhou Province, China. 
This work was supported by the Knowledge Innovation Program of the Chinese Academy of Sciences (KZCX2-YW-306-3) and the National Natural Science Foundation of China (40721002, 40573048 and 40872212).

1 Keene W C, Galloway J N. The biogeochemical cycling of formic and acetic acids through the troposphere: An overview of current understanding. Tellus B, 1988, 40: 322-334

2 Peña R M, García S, Herrero C, et al. Organic acids and aldehydes in rainwater in a northwest region of Spain. Atmos Environ, 2002, 36: 5277-5288

3 Tanner P A, Law P T. Organic Acids in the Atmosphere and Bulk Deposition of Hong Kong. Water Air Soil Pollut, 2003, 142: 279-297

4 Wang H, Shoote D. Low molecular weight dicarboxylic acids in PM10 in a city with intensive solid fuel burning. Chemosphere, 2004, 56: 725-733

5 Jiang W. Organic and inorganic geochemical characteristic of rainwater in Zunyi, Guizhou (in Chinese). Dissertation for the Doctoral Degree. Guiyang: Institute of Geochemistry, CAS, 2007. 50-178

6 Liu C, He LY, Niu Y W, et al. Wet deposition of low molecular weight carboxylic acids in Shenzhen (in Chinese). Res Environ Sci, 2007, 20: 20-25

7 Xu G, Lee X Q, Lü Y C, et al. Seasonal variations of carboxylic acids and their contributions to the rainwater acidity: A case study of Guiyang City and Shangzhong Town, China. Chinese Sci Bull, 2010, 55: $1667-1673$

8 Galloway J N, Keene W C, Likens G E, et al. The composition of precipitation in remote areas of the world. J. Geophys Res, 1982, 87: 8771-8786

9 Yu S, Gao C, Cheng Z. et al. An analysis of chemical composition of different rain types in Minnan Golden Triangle' region in the southeastern coast of China. Atmos Res, 1998, 47: 245-269

$10 \mathrm{Xu}$ G, Lee X, Huang R S, et al. Low molecular carboxylic acids in precipitation of Guiyang, China (in Chinese). Earth Environ, 2007, 35: $46-50$

11 Sabbioni C, Ghedini N, Bonazza A. Organic anions in damage layers on monuments and buildings. Atmos Environ, 2003, 37: 1261-1269

12 Kumar N, Kulshrestha U C, Khare P, et al. Measurements of formic and acetic acid levels in the vapour phase at Dayalbagh, Agra, India. Atmos Environ, 1996, 30: 3545-3550

13 Keene W C, Galloway J N. Considerations regarding sources for formic and acetic acids in the troposphere. J Geophys Res, 1986, 91: 14466-14474

14 Kawamura K, Kasukabe H, Barrie L A. Source and reaction pathways of dicarboxylic acids, ketoacids and dicarbonyls in arctic aerosols: One year of observations. Atmos Environ, 1996, 30: 1709-1722

$15 \mathrm{Hu} \mathrm{M}$, Zhang J, Wu Z J. Chemical characteristic of rainwater and wash out effect on particles in Beijing (in Chinese). Sci China Ser B-Chem Sci, 2005, 35: 169-176

16 Chen Z L, Wang Y B. The function of organic compounds in acidification in rainwater (in Chinese). Environ Chem, 1991, 10: 1-13

17 He X H. Observations of formic and acetic acids in rainwater (in Chinese). Dissertation for the Master Degree. Beijing: Chinese Academy of Meteorological Science, 2008. 35-48

18 Fornaro A, Ivano G R. Wet deposition and related atmospheric chemistry in the Sao Paulo Metropolis, Brazil: Part 2-contribution of formic and acetic acids. Atmos Environ, 2003, 37: 117-128

19 Xu G. Study on carboxylic acids in rainwater in the Southwest China: A case study of Guiyang City and Shangzhong Town (in Chinese). Dissertation for the Doctoral Degree. Guiyang: Institute of Geochemistry, CAS, 2006. 70-124

20 Kumar N, KulShrestha U C, Saxena A, et al. Formate and acetate levels compared in monsoon and winter rainwater at Dayalbagh, Agra (India). J Atmos Chem, 1996, 23: 81-87

21 Avery G B, Willey J D, Kieber R J. Diurnal variations in major rainwater components at a coastal site in North Carolina: North America. Atmos Environ, 2001, 35: 3927-3933

22 Souza S R, Vasconcellos P C, Carvalho L R. Low molecular weight carboxylic acids in an urban atmosphere: Winter measurements in Sao Paulo City, Brazil. Atmos Environ, 1999, 33: 2563-2574

23 Talbot R W, Beecher K M, Harriss R C, et al. Atmospheric geochemistry of formic and acetic acids at a mid-latitude temperate site. J Geophys Res, 1988, 93: 1638-1652

24 Millet M, Wortham H, Sanusi A, et al. Low molecular weight organic acids in fogwater in an urban area: Strasbourg (France). Sci Total Environ, 1997, 20: 57-65

25 Sakugawa H, Kaplan I R, Shepard L S. Measurements of $\mathrm{H}_{2} \mathrm{O}_{2}$, aldehydes and organic acids in Los Angeles Rainwater: Their sources and deposition rates. Atmos Environ B: Urban Atmos, 1993, 27: 203-219

26 Zhang Y L, Lee X Q, Cao F, et al. Chemical characteristics and sources of organic acids in precipitation at a semi-urban site in Southwest China. Atmos Environ, 2010, doi:10.1016/j.atmosenv.2010.09.067

Open Access This article is distributed under the terms of the Creative Commons Attribution License which permits any use, distribution, and reproduction in any medium, provided the original author(s) and source are credited. 